\title{
Laparoscopic Management of Leiomyoma Developing from Rudimentary Horn in Mayer- Rokitansky-Küster-Hauser Syndrome
}

\begin{abstract}
Keywords: Leiomyoma; Congenital uterine anomalies; MayerRokitansky-Küster-Hauser Syndrome; Amenomhea; Infertility

Abstract

Various congenital a nomalies of the mullerian system have so far been described. Our case with MRKH syndrome had two rudimentary homs, and had also a leiomyoma arising from the left rudimentary hom. The patient was presented to our department because of primary amenomhoea and infertility. Clinical examination revealed a blind vaginal pouch of $3 \mathrm{~cm}$ in size and mass was palpated in the left adnexal region measuring about $5 \mathrm{~cm}$ in size. At the diagnostic laparoscopy examination, two rudimentary homs were observed to be connected to each other with a fibrous band, and there was a leiomyoma measuring $60 \times 50 \mathrm{~mm}$ in size originating from the left hom, both of the fallopian tubes and ovaries were nomal. The leiomyoma was laparoscopically removed. Using this method have led to successful Clinical outcomes. We sought to present the case of the myoma and its laparoscopic management associated with rarely encountered MRKH syndrome. Although rarely encountered, it should be kept in mind that patients with MRKH syndrome may develop leiomyomas from rudimentary hom. And also laparoscopy is recommended for the diagnosis and treatment of this diseases.
\end{abstract}

\section{Introduction}

The prevalence of congenital uterine anomalies appears to be $6.7 \%$ in fertile population and it is found $7.3 \%$ in an infertile population while it is observed to be $16.7 \%$ in those with recurrent miscarriage [1]. Mayer-Rokitansky- Kuster-Hauser (MRKH) syndrome, the most severe anomaly of Mullerian system, was first described by Mayer, Rokitansky, Kuster and Hauser [2]. The etiologic factors of this syndrome is not fully understood, and environmental and genetic factors are thought to play a role [3]. In MRKH syndrome, the vagina and uterus is congenitally absent, both ovaries are of normal size and fallopian tubes are normal, rudimentary uterine horns may be present in this syndrome [4,5]. A case of myoma associated with MRKH syndrome was first reported in 1977 [6]. We sought to present the case of the myoma associated with rarely encountered $\mathrm{MRKH}$ syndrome.

\section{Case Report}

A 41-years old patient presented to Gynecology Department of Taksim Education and Research Hospital because of primary amenorrhea and infertility in 2013. The patient had a past history of primary amenorrhea and some 20 years back she applied to Gynaecology Department but could not know what diagnosis it was. Clinical examination revealed a blind vaginal pouch of $3 \mathrm{~cm}$ in size and mass was palpated in the left adnexal region measuring

\section{Journal of \\ Andrology \& Gynaecology}

\begin{abstract}
Suleyman Salman², Murat Bozkurt ${ }^{1 *}$, Ayse Ender Yumru² $^{2}$ Abdulhamit Bozyigit' ${ }^{2}$, Berker Kavsi ${ }^{2}$ and Serkan Kumbasar ${ }^{3}$

${ }^{1}$ Kafkas University Medical Faculty, Department of Obstetrics and Gynecology, Kars, Turkey

${ }^{2}$ Taksim Education and Research Hospital, Department of Obstetrics and Gynecology Istanbul, Turkey

${ }^{3}$ Maternity and Children's Hospital, Department of Obstetrics and Gynecology, Sakarya, Turkey

\section{*Address for Correspondence}

Murat Bozkurt, MD, Caucasus University Campus Health Care Research and Development Hospital, KARS, Turkey, Tel: +905322279072/+905056330044; Fax: 047422514 30; E-mail: jindrmb@yahoo.com
\end{abstract}

Submission: 21 October 2013 Accepted: 19 December 2013

Published: 27 December 2013

Reviewed \& Approved by: Sunil Halder

Assistant Professor, Department of Obstetrics and Gynecology

Center for Women's health Research , Meharry Medical College

about $5 \mathrm{~cm}$ in size. Physical examination revealed normal bilateral breasts, normal axillary and pubic hair patterns. Transabdominal ultrasonography showed a solid mass in the left adnexal region. Chromosomal investigation of our case indicated a normal karyotype of 46, XX. Diagnostic laparoscopy revealed that the uterus was absent and there were two rudimentary horns connected with each other by a fibrous band, and there was myoma-like mass $60 \times 50 \mathrm{~mm}$ arising from the left rudimentary uterine, both ovaries and fallopian tubes were normal in appearance (Figure 1 and Figure 2). The mass was laparoscopically excised. The patient was discharged the following day, histopathological examination confirmed that the mass was a leiomyoma.

\section{Discussion}

Mayer-Rokitansky-Kuster-Hauser (MRKH ) syndrome is a rare disorder described as aplasia or hypoplasia of uterus and vagina due to

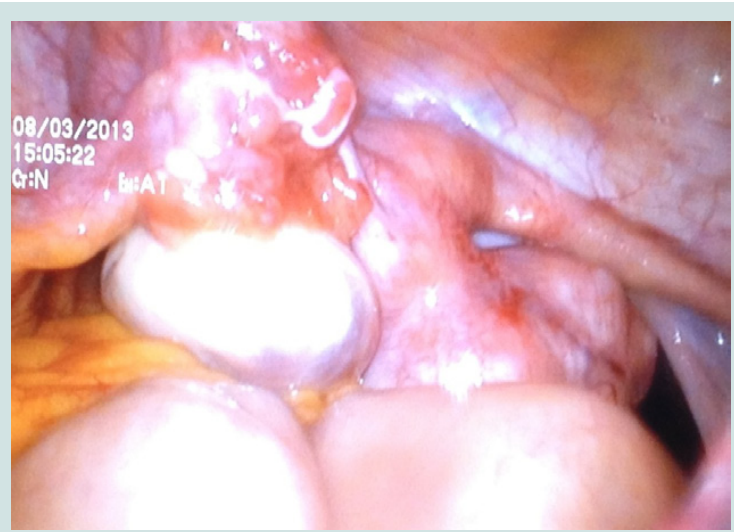

Figure 1: A rudimentary left uterine horn with tube and ovary. A leiomyoma $60 \times 50 \mathrm{~mm}$ is shown. 
Citation: Salman S, Bozkurt M, Yumru AE, Bozyigit A, Kavsi B, et al. Laparoscopic Management of Leiomyoma Developing from Rudimentary Horn in MayerRokitansky-Küster-Hauser Syndrome. J Androl Gynaecol. 2013;1(2): 2.

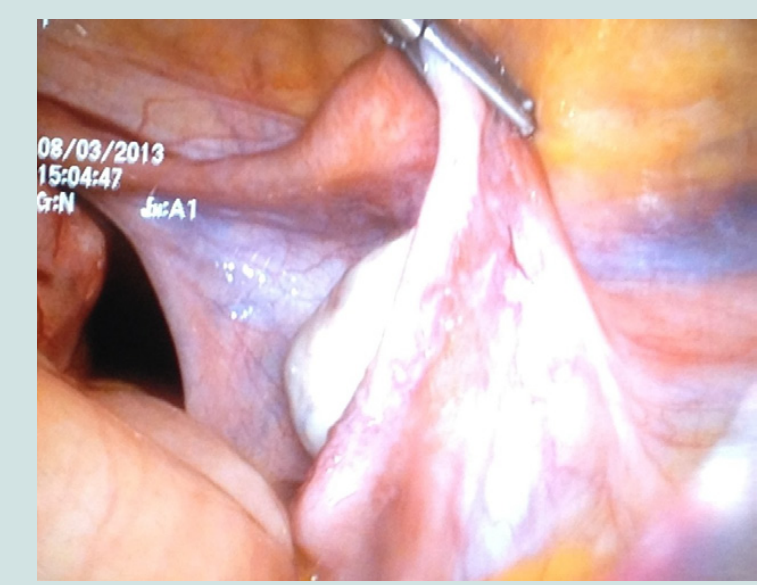

Figure 2: A rudimentary right uterine horn with tube and ovary.

early arrest in development of Mullerian duct. The incidence reported is one out of 4.500 women [7]. Diagnosis of MRKH syndrome is often delated untill late puberty. The symptoms for presentation are amenorrhea, infertility and pelvic pain. This rare syndrome described as aplasia or hypoplasia of uterus and vagina due to the early arrest in development of Mullerian duct. These patients have the ovaries and fallopian tubes of normal functions and most of whom have also two uterine remnants of different sizes [3]. Incidence of leiomyoma of uterus is very high in the general female population. But only few cases of leiomyoma have been reported in women with MRKH syndrome [8-10].

The clinical symptoms associated with the pelvic in patients with MRKH have to be carefully investigated; uterine remnants in patients with MRKH syndrome are composed of fibromuscular tissue and a leiomyoma may develop from this tissue; the cases of uterine leiomyoma developing from uterine remnant have been reported in the literatüre [11]. Leiomyomas of the uterus are estrogen dependent tumours. The etiopathogenesis of leiomyoma from the normal uterus smooth muscle cells is not known. Their growth has been associated with genetic predisposition, hormones and few growth factors. Mullerian ducts have smooth muscle cells at their proximal ends, which probably may lead to the growth of leiomyoma from the rudimentary uterus in MRKH syndrome. However, the exact etiopathogenesis of leiomyoma from the rudimentary uterus in MRKH syndrome is not known [12].

Differential diagnosis of leiomyoma of rudimentary uterus in MRKH syndrome includes ovarian fibroma, gastrointestinal stromal tumour (GIST) of intestine and extravesical leiomyoma of urinary bladder [12].

Myomas originating from uterine remnanats may cause pelvic pain; however, they may not give any indications as it was in our cases and may be detected by diagnostic procedures. Initial investigation in woman with MRKH syndrome with leiomyoma is radiologic modalities like ultrasonography, computed tomography and magnetic resonance imaging. However, laparoscopic evaluation is more accurate to evaluate the pelvic pathologies. Also, laparoscopy can be used as a method of diagnosis and treatment when a pelvic mass is detected in patients with MRKH syndrome. The surgical treatment of leiomyoma can be done by laparoscopy or laparotomy. In the literature, Tsin et al. have first reported the successful laparoscopic management of the $8.5 \mathrm{~cm}$ size leiomyoma uterine with MRKH syndrome. Laparoscopy have several advantages compared to laparotomy [13]. The major advantages of laparoscopic surgery are that it provides adequate visualization of the entire abdominal cavity and localization of pathology. And also this methods reduced morbidity, smaller, cosmetically acceptable wounds leads to early recovery. In our case, laparoscopic surgery was done sucessfully and best clinical outcomes were obtained.

In conclusion, leiomyoma may, albeit rarely, develop from uterine remnant, so it must be borne in mind that leiomyoma may be included in the differential diagnosis of patients with MRKH presenting with a pelvic mass. And also we suggested that laparoscopy can be used for the diagnosis and treatment of this disease.

\section{References}

1. Saravelos SH, Cocksedge KA, Li TC (2008) Prevalence and diagnosis of congenital uterine anomalies in women with reproductive failure: a critical appraisal. Hum Reprod Update 14: 415- 429.

2. Rokitansky K (1838) Uber die sogenannten Verdoppelun- gen des Uterus. Med JB Ost Staates 26: 39- 42.

3. Deligeoroglou E, Kontoravdis A, Makrakis E, Christopoulos P, Kountouris A, et al. (2004) Development of leiomyomas on the uterine remnants of two women with Mayer- Rokitansky- Kuster- Hauser syndrome. Fertil Steril 81: 1385- 1387.

4. Giatras K, Licciardi F, Grifo JA (1998) Laparoscopy for pelvic pain in the Mayer- Rokitansky- Kuster- Hauser syndrome. A case report. J Reprod Med 43: 203-205.

5. Cakmak H, Arici A (2006) Mullerian Duct Anomalies. Turkiye Klinikleri J Pediatr Sci 2: 23-29.

6. Beecham CT, Skiendzielewski J (1977) Myoma in association with MayerRokitansky- Kuster- Hauser syndrome. Am J Obstet Gynecol129: 346- 348.

7. Alfonsa Pizzo, Antonio Simone Laganà, Emanuele Sturlese, Giovanni Retto, et al. (2013) Mayer-Rokitansky-Kuster-Hauser Syndrome: Embryology, Genetics and Clinical and Surgical Treatment. ISRN Obstet Gynecol 2013: 628717

8. Deligeoroglou E, Kontoravdis A, Makrakis E, Christopoulos P, Kountouris $A$, et al. (2004) Develpoment of leiomymas on the uterine remnants of two women with Mayer-Rokitansky-Kuster-Hauser syndrome. Fertil Steril 81:1385-1387.

9. Dandu S, Jones SE, Okeahialam MG (2000) Mayer-Rokitansky-KusterHauser syndrome associated with chromosomal abnormality and fibroid arising from the rudimentary uterine horn. J Obstet Gynecol 20: 98.

10. Edmonds DK (2003) Multiple fibroids in a postmenopausal women with Mayer-Rokitansky-Kuster-Hauser syndrome. J Pediatr Adolesc Gynecol 16: 65-66.

11. Jadoul P, Pirard C, squifflet J, Smets M, Donnez J (2004) Pelvic mass in women with Mayer- Rokitansky- Kuster- Hauser syndrome. Fertil Steril 81: 203-204.

12. Rawat KS, Buxi T, Yadav A, Ghuman SS, Dhawan S (2013) Large leiomyoma in a woman with Mayer-Rokitansky-Kuster-Hauser syndrome. J Radiol Case Rep 7: 39-46.

13. Tsin DA, Waters TK, Granato RC (2000) Laparoscopic myomectomy in a patient with Mayer-Rokitansky-Kuster-Hauser syndrome. J Am Assoc Gynecol Laparosc 7: 411-413.

Copyright: (c) 2013 Salman S, et al. This is an open access article distributed under the Creative Commons Attribution License, which permits unrestricted use, distribution, and reproduction in any medium, provided the original work is properly cited. 